Goldschmidt 2021 Abstract

https://doi.org/10.7185/gold2021.7148

\section{Coupled cadmium and climatic stress increase agricultural greenhouse gas emissions}

\author{
SOEREN DRABESCH ${ }^{1}$, BRITTA PLANER-FRIEDRICH ${ }^{2}$, \\ JOSÉ MIGUEL LEÓN-NININ ${ }^{3}$, JUAN SALVADOR \\ LEZAMA-PACHECO ${ }^{4}$, SCOTT FENDORF ${ }^{4}$, ANDREAS \\ KAPPLER $^{1}$ AND E. MARIE MUEHE ${ }^{5}$ \\ ${ }^{1}$ University of Tuebingen \\ ${ }^{2}$ Environmental Geochemistry, Bayreuth Center for Ecology and \\ Environmental Research, University of Bayreuth \\ ${ }^{3}$ University of Bayreuth \\ ${ }^{4}$ Stanford University \\ ${ }^{5}$ Helmholtz Center for Environmental Science UFZ \\ Presenting Author: soeren.drabesch@ifg.uni-tuebingen.de
}

Agricultural soils contribute up to $5 \%$ to total anthropogenic greenhouse gas (GHG) emissions. The heavy metal cadmium has been accumulating in agricultural soils, due to atmospheric depositions and modern agricultural processes using impure, metal-bearing phosphate fertilizers [Grant et al. 2012]. Cadmium has no metabolic function and is considered toxic to microorganisms that produce most of the GHG emitted from agricultural soils. A change in Earth's climate alters microbial activity [Bardgett et al. 2008] and may also shift cadmium bioavailability due to, for example, altered binding characteristics within the soil matrix. Thus, it is important to understand how climate impacts GHG emissions from cadmiumbearing agricultural soils. We hypothesize that future climate and increasing soil cadmium combined, will reduce GHG emissions from agricultural topsoils compared to when cadmium contaminated soils are exposed to today's climate.

In climatically controlled incubation chambers, vertical soil mesocosms filled with agricultural soils bearing three different cadmium concentrations $\left(0.24,0.78,4.42 \mu \mathrm{g}\right.$ cadmium $\mathrm{kg}^{-1}$ dry soil) were exposed to different climatic conditions for 7 weeks in a multifactorial design. Increasing atmospheric $\mathrm{CO}_{2}$ concentration to $800 \mathrm{ppm}_{\mathrm{v}}$ and atmospheric temperature by $4^{\circ} \mathrm{C}$ (a likely scenario 2100 according to IPCC 2017) relative to today's climatic conditions were simulated. Soils of low cadmium contamination emitted more $\mathrm{N}_{2} \mathrm{O}$ and $\mathrm{CO}_{2}$ under today's climatic conditions, compared to soils with background cadmium concentrations. Under future climatic conditions, soil cadmium did not affect $\mathrm{CO}_{2}$ emissions yet increased $\mathrm{N}_{2} \mathrm{O}$ emissions compared to soils with background cadmium concentrations. As $\mathrm{N}_{2} \mathrm{O}$ has a 265 times higher warming potency than $\mathrm{CO}_{2}$, the global warming potential of GHGs emitted from low cadmium contaminated soils exposed to future climatic conditions was almost two times higher compared to soils with background cadmium and exposed to today's climatic conditions. To reason our surprising findings that contradict our hypothesis, we will present a combination of geochemical and microbial ecology data to explain differences in cadmium binding to the soil matrix and nitrogen cycling in the different incubation set-ups.

Our results indicate that low topsoil cadmium concentrations can affect soil-induced GHG emissions under a simulated future climate, warranting further investigation on a field scale. 